\title{
Conserved and breed-specific differences in the cervical transcriptome of sheep with divergent fertility at the follicular phase of a natural oestrus cycle
}

Laura Abril-Parreño ${ }^{1,2}$, Kieran G. Meade ${ }^{3}$, Anette Kristine Krogenæs ${ }^{4}$, Xavier Druart ${ }^{5}$, Sean Fair ${ }^{1{ }^{*+}}$ and Paul Cormican ${ }^{2+}$

\begin{abstract}
Background: The outcome of cervical artificial insemination (Al) with frozen-thawed semen in sheep is limited by the inability of sperm to traverse the cervix of some ewe breeds. Previous research has demonstrated that cervical sperm transport is dependent on ewe breed, as sperm can traverse the cervix in greater numbers in some higher fertility ewe breeds. However, the molecular mechanisms underlying ewe breed differences in sperm transport through the cervix remain unknown. In this study, we aimed to characterise the cervical transcriptome of four European ewe breeds with known differences in pregnancy rates following cervical Al using frozen-thawed semen at the follicular phase of a natural oestrous cycle. Cervical post mortem tissue samples were collected from two Irish ewe breeds (Belclare and Suffolk; medium and low fertility, respectively) and from two Norwegian ewe breeds (Norwegian White Sheep (NWS) and Fur; high fertility compared to both Irish breeds) at the follicular phase of a natural oestrous cycle ( $n=8$ to 10 ewes per breed).
\end{abstract}

Results: High-quality RNA extracted from biopsies of the mid-region of the cervix was analysed by RNA-sequencing and Gene Ontology (GO). After stringent filtering ( $P<0.05$ and FC $>1.5)$, a total of 11, 1539 and 748 differentially expressed genes (DEGs) were identified in Belclare, Fur and NWS compared to the low fertility Suffolk breed, respectively. Gene ontology analysis identified significantly enriched biological processes involved in muscle contraction, extracellular matrix (ECM) development and the immune response. Gene co-expression analysis revealed similar patterns in muscle contraction and ECM development modules in both Norwegian ewe breeds, which differed to the Irish ewe breeds.

Conclusions: These breed-specific biological processes may account for impaired cervical sperm transport through the cervix in sheep during the follicular phase of the reproductive cycle. This novel and comprehensive dataset provides a rich foundation for future targeted initiatives to improve cervical Al in sheep.

Keywords: Ovine, Cervix, RNA-sequencing, Fertility

\footnotetext{
* Correspondence: sean.fair@ul.ie

†Sean Fair and Paul Cormican contributed equally to this work.

'Laboratory of Animal Reproduction, Department of Biological Sciences,

School of Natural Sciences, Biomaterials Research Cluster, Bernal Institute,

Faculty of Science and Engineering, University of Limerick, Limerick, Ireland

Full list of author information is available at the end of the article
}

(c) The Author(s). 2021 Open Access This article is licensed under a Creative Commons Attribution 4.0 International License, which permits use, sharing, adaptation, distribution and reproduction in any medium or format, as long as you give appropriate credit to the original author(s) and the source, provide a link to the Creative Commons licence, and indicate if changes were made. The images or other third party material in this article are included in the article's Creative Commons licence, unless indicated otherwise in a credit line to the material. If material is not included in the article's Creative Commons licence and your intended use is not permitted by statutory regulation or exceeds the permitted use, you will need to obtain permission directly from the copyright holder. To view a copy of this licence, visit http://creativecommons.org/licenses/by/4.0/. The Creative Commons Public Domain Dedication waiver (http://creativecommons.org/publicdomain/zero/1.0/) applies to the data made available in this article, unless otherwise stated in a credit line to the data. 


\section{Background}

The complexity of cervical anatomy in sheep usually precludes the transcervical deposition of sperm during AI. Cervical AI with frozen-thawed semen yields pregnancy rates of less than $30 \%$ worldwide [1-3]. An exception to this is in Norway, where vaginal (shot-in-thedark) insemination with frozen-thawed semen to a natural oestrous is performed by farmers themselves and yields pregnancy rates in excess of $70 \%$ in NWS, which makes up most of their national flock [4]. The reason for the successful pregnancy rates to AI in Norway has been the focus of a number of studies by our group. Earlier studies found no differences in ram/semen parameters between countries but did identify significant ewe breed effects following cervical AI with frozenthawed semen, with pregnancy rates of 18, 28, 44 and $77 \%$ for Suffolk, Texel, Belclare and Finnish Landrace ewes respectively $[2,5]$.

Further investigation into the ewe breed effects demonstrated no differences between breeds in terms of oocyte quality [6] or in hormonal profiles during the periovulatory period. Furthermore, analysis of the luteinising hormone surge and time of ovulation relative to pessary removal [7] also failed to yield discernible differences. Interestingly, while fertilisation rates following laparoscopic AI with frozen-thawed semen were similar between Suffolk and Belclare ewes, both fertilisation rates and accessory sperm number following cervical AI with frozen-thawed semen was significantly higher in Belclare than the Suffolk ewes. This demonstrates that frozen-thawed sperm can traverse the cervix in greater numbers in some ewe breeds around the time of ovulation [5]. A follow on study reported ewe breed differences in rheological characteristics of cervical mucus, which may be related to the higher number of frozenthawed sperm penetrating cervical mucus from Belclare than that from Suffolk ewes [8]. Thus, the migration of sperm through the cervix appears to be the critical limiting factor for the success of cervical AI, especially when frozen-thawed semen is used.

A recent study by our group compared the gross anatomy (cervical length, number of cervical rings, the appearance of the external os type) as well as mucus production and viscosity across Irish, Norwegian and French ewe breeds at both a synchronised and a natural cycle [9]. This study did not detect a relationship between these cervical anatomical parameters or gross mucus properties and previously reported ewe breed differences in pregnancy rates following cervical AI with frozen-thawed semen. Although, there was a significant effect of phase of the cycle on mucus production, viscosity and colour. Follicular mucus was more abundant, less viscous and clearer in colour than luteal mucus, and it is in part due to the $O$-glycosylated proteins, called mucins. In a recent study, we characterized the $O$-glycan composition in the cervical mucus of six European ewe breeds at the follicular phase [10]. This was from the same animals used in the current study plus two additional breeds. We identified that the use of exogenous hormones for oestrous synchronization did not affect the $O$-glycan composition in the high fertility ewe breeds, but it did in the other ewe breeds. We also identified differences in the O-glycan composition between ewe breeds within the same type of oestrous cycle.

These findings point to potentially more subtle biochemical and/or molecular differences in cervical physiology. Thus, we proposed that a molecular approach is required to interrogate the cervical biology of these economically important ewe breeds to understand the mechanisms regulating sperm transport at the follicular phase of a natural oestrous cycle. A natural cycle was chosen as shot-in-the dark AI is performed to a natural oestrous in Norway, but to a synchronised oestrous in most other countries internationally. We aimed to profile the transcriptome of the cervix in two Norwegian and two Irish ewe breeds, with known differences in pregnancy rates following cervical AI, with frozenthawed semen at the follicular phase of a natural oestrous cycle.

\section{Results}

Divergence in gene expression profiles most evident between Suffolk and Norwegian ewe breeds

RNA-sequencing data from 38 cervical biopsies of four European ewe breeds with known differences in pregnancy rates following cervical AI with frozen-thawed semen was plotted using principal component analysis (PCA) to assess the distribution of the samples within ewe breed and between ewe breeds. The Suffolk was used as a reference breed for all analyses as it has the lowest fertility. Results showed no clear segregation between the two Irish ewe breeds, whereas comparing Fur and NWS against Suffolk showed a distinct grouping as illustrated on the PCA plot (Fig. 1). This data suggested the highest fertility ewe breeds from Norway had distinct gene expression profiles compared to the low fertility Suffolk breed.

\section{Differential gene expression analysis identifies breed- specific differences in gene expression profiles}

Using stringent statistical filtering criteria $(P<0.05$ and FC $>1.5$ ), data analysis identified extensive alterations in gene expression between ewe breeds at the follicular phase of a natural oestrous cycle. RNA-sequencing detected 11 DEGs (10 down-regulated and 1 gene upregulated), 1539 (723 down-regulated and 816 upregulated genes) and 748 (279 down-regulated and 469 up-regulated genes) in Belclare, Fur and NWS compared 

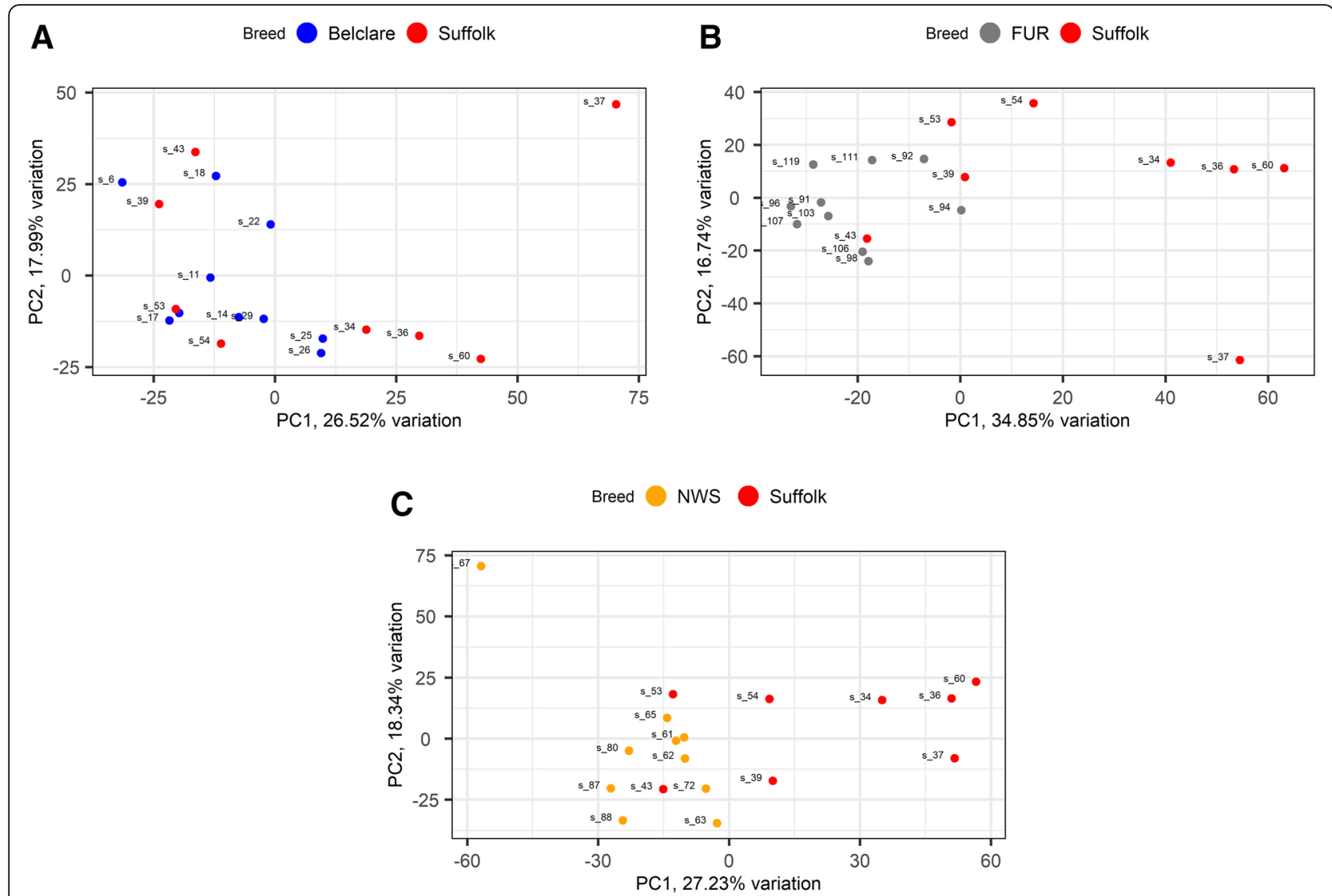

Fig. 1 Principal component analysis (PCA) plots show distribution of RNA-sequencing samples, where colours indicate the two ewe breeds in each comparison: Belclare (A), Fur (B) and Norwegian White Sheep (NWS) (C) compared to Suffolk at the follicular phase of a natural oestrous cycle

to the low fertility Suffolk breed (reference level), respectively. Fur had the highest difference in terms of number of DEGs compared to Suffolk breed, which is the reference level due to its lowest pregnancy rates following cervical AI using frozen-thawed semen. Volcano plots show the $\log 2$ fold-change of the top 20 DEGs in Suffolk compared to Belclare, Fur and NWS ewes (Fig. 2).

Specific gene expression differences were observed in the cervical tissue from the four ewe breeds at the follicular phase of a natural cycle. The top 5 DEGs in Belclare compared to Suffolk are shown in Supplementary Table 1. Genes such as the Early Growth Response 1 gene (EGR1), NADPH Oxidase 5 (NOX5) and Surfactant Associated 2 (SFTA2) were significantly up-regulated in Suffolk compared to Belclare. Only one DEG was significantly down-regulated in Suffolk compared to Belclare ewes, which was the TBC/LysM-associated domain containing 1 (TLDC1) gene.

A total of 1539 DEGs were up-regulated in Suffolk compared to Fur ewes, of these the top 5 are shown in Supplementary Table 2. This list included the Mitochondrially Encoded Cytochrome C Oxidase I (COX-1) with a $\mathrm{FC}$ of 68 . Other genes included encoded secreted proteins such as the folate gamma receptor (FLR3) and the Solute Carrier Family 3 Member 1 (SLC3A1). The top 5 DEGs downregulated in Suffolk compared to Fur included genes such as DKK2 (Dickkopf WNT Signaling Pathway Inhibitor 2) and SFRP2 (Secreted Frizzled Related Protein 2).

The top 5 DEGs of up-regulated genes in Suffolk compared to NWS included novel genes, the Folate receptor gamma (FOLR3) gene and the Solute Carrier Family 3 Member 1 (SLC3A1) gene (Supplementary Table 3). The top 5 DEGs down-regulated in Suffolk compared to NWS is also shown in Supplementary Table 3. These included genes involved in the control of the properties of the membrane associated cytoskeleton by the expression of amphiphysin $(A M P H)$, the Calcium voltage-gated channel subunit alpha1 S (CACNA1S), Secreted Frizzled Related Protein 2 (SFRP2) and Protocadherin Related 15 (PCDH15).

Gene ontology analysis identified enrichment of muscle development and sterol biosynthetic biological processes No GO subcategory showed significant enrichment between Belclare and Suffolk ewes as relatively few DEGs were available for analysis. The top 5 of biological processes up-regulated and down-regulated in Fur 

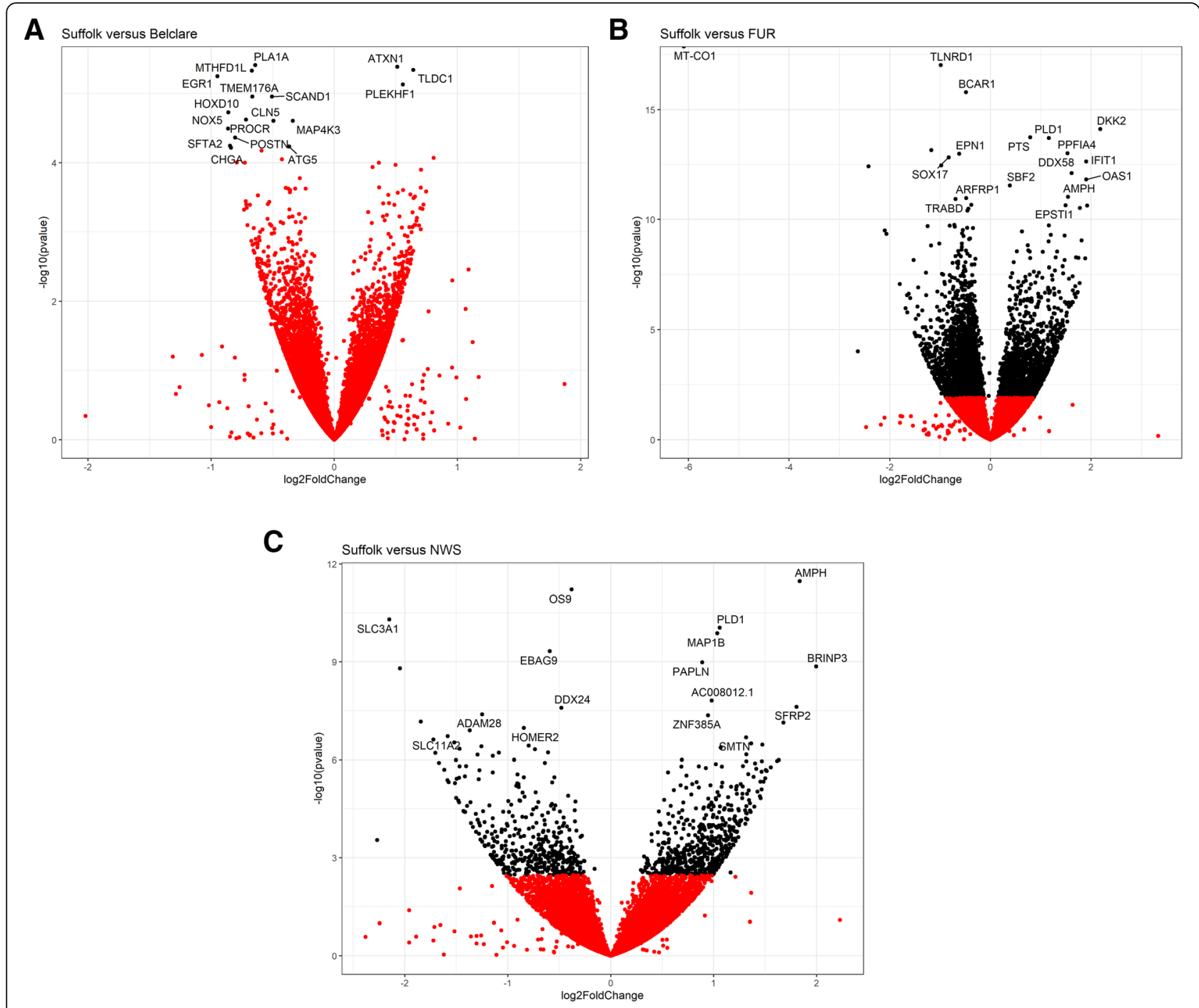

Fig. 2 Gene expression data presented as volcano plots at the follicular phase of a natural oestrous cycle for Belclare (A), Fur (B) and Norwegian White Sheep (NWS) (C) compared to the low fertility Suffolk breed using log values of the FC and $P$-value. Each point represents a single gene, with those in black representing genes that survived the cut off thresholds of adjusted $P<0.05$ and FC $>1.5$ and red points represent genes with a $P>0.05$

compared to Suffolk ewes is shown in Table 1. These included down-regulated pathways involved in sterol biosynthesis and vascular transport in Fur compared to Suffolk. However, up-regulated pathways in Fur are involved in muscle contraction and development. In addition, GO analysis revealed down-regulated pathways in NWS related to anatomical structure morphogenesis, response to chemicals and stimulus (Table 1). We also identified up-regulated pathways in NWS compared to the low fertility Suffolk breed that are involved in muscle development and cell adhesion.

\section{Extensive differences in the immune profile of Fur and NWS compared to the low fertility Suffolk}

A number of immune genes were also significantly differentially expressed between Suffolk and the Norwegian ewe breeds. Comparing the Fur to the Suffolk, the genes IGF2 (Insulin-like growth factor 2) and SAA1 (Serum Amyloid A1) were significantly up-regulated. In contrast, more immune genes were significantly reduced in the Suffolk compared to the Fur, and these were spread across multiple functional classes including cell-surface receptors (referred to as clusters of differentiation (CD)), Toll-like receptors (TLRs), cytokines, chemokines, acute phase proteins and genes involved in the antimicrobial response. Of particular note, TLR1, TLR6 and multiple chemokines genes including CXCL9, CXCL10 and CXCL11 were all down-regulated $(P<0.05)$. Cytokines IL17B, IL18, IL33, IL34 and TGF $\beta$ (Transforming Growth Factor Beta) are also reduced in expression. Lactoperoxidase $(L P O)$ and multiple genes encoding members of the S100 family of calcium regulated multifunctional peptides (S100B, S100A8, S100A9 and 
Table 1 Top 5 of biological processes enriched pathways down and up-regulated in Fur (A) and Norwegian White Sheep (NWS) (B) compared to Suffolk at the follicular phase of a natural oestrous cycle

\begin{tabular}{|c|c|c|}
\hline Term name & Term ID & $P$-value \\
\hline \multicolumn{3}{|l|}{ A } \\
\hline \multicolumn{3}{|l|}{ Down-regulated in Fur compared to Suffolk } \\
\hline Sterol biosynthetic process & GO:0016126 & $<0.001$ \\
\hline Cholesterol biosynthetic process & GO:0006695 & $<0.001$ \\
\hline Small molecule biosynthetic process & GO:0044283 & $<0.001$ \\
\hline Fatty acid derivative biosynthetic process & GO:1901570 & $<0.001$ \\
\hline Vascular transport & GO:0010232 & $<0.001$ \\
\hline \multicolumn{3}{|l|}{ Up-regulated in Fur compared to Suffolk } \\
\hline System process & GO:0003008 & $<0.001$ \\
\hline Multicellular organismal process & GO:0032501 & $<0.001$ \\
\hline Muscle structure development & GO:0061061 & $<0.001$ \\
\hline Anatomical structure development & GO:0048856 & $<0.001$ \\
\hline Tissue development & GO:0009888 & $<0.001$ \\
\hline \multicolumn{3}{|l|}{ B } \\
\hline \multicolumn{3}{|l|}{ Down-regulated in NWS compared to Suffolk } \\
\hline Anatomical structure morphogenesis & GO:0009653 & $<0.05$ \\
\hline Response to chemical & GO:0006936 & $<0.05$ \\
\hline Response to stimulus & GO:0050896 & $<0.05$ \\
\hline Multicellular organismal process & GO:0032501 & $<0.05$ \\
\hline Positive regulation of multicellular organismal process & GO:0051240 & $<0.05$ \\
\hline \multicolumn{3}{|l|}{ Up-regulated in NWS compared to Suffolk } \\
\hline System process & GO:0003008 & $<0.001$ \\
\hline Muscle structure development & GO:0061061 & $<0.001$ \\
\hline Cell adhesion & GO:0007155 & $<0.001$ \\
\hline Multicellular organismal process & GO:0032501 & $<0.001$ \\
\hline Anatomical structure development & GO:0048856 & $<0.001$ \\
\hline
\end{tabular}

S100A12) were similarly reduced in expression. A similar profile in DEGs was evident comparing the NWS to the Suffolk. Suffolk display elevated levels of the receptors CD14, CXCR4 and the chemokine CXCL14 as well as increased $I G F 2$ and $S A A 1$. Multiple $C D$ receptors including $C D 1 E$, $C D 44$ and $C D 274$ were decreased in expression as was the expression of the chemokine CXCL11 and multiple cytokines (IL1A, IL17B, IL33, IL34 and TGF $\beta$ ).

\section{Gene co-expression analysis across high and low fertility ewe breeds}

RNA-sequencing data were subsequently used to perform a co-expression analysis, which allow us to identify key modules representing genes with similar expression patterns between ewe breeds. Co-expression analysis revealed six modules, from which module 1 and module 3 revealed different co-expression patterns between Irish (Suffolk and Belclare) and Norwegian ewe breeds (Fur and NWS; Fig. 3). Module 1 contained enriched pathways related to muscle contraction and ECM development, which were significantly enriched in Fur and NWS with lower levels of expression in Belclare and Suffolk ewes $(P<0.05$; Fig. 3$)$.

In addition, module 4 showed enriched pathways related with skin development and cell-cell junction, which had higher expression in Fur and lower expression in the low fertility Suffolk breed $(P<0.05)$. The top 5 of main regulators or hub genes of module 4 included genes involved in the keratinization process such as KRT78 (Keratin type II cytoskeletal 78), genes encoding calcium-binding proteins that play an antimicrobial function (S100A8, S100A9, S100A12) and TRIM29 (Tripartite Motif Containing 29) which is also involved in the response to viral and bacterial infections.

\section{Discussion}

The cervix is a complex fibrous structure composed of two major types of tissue. The stromal tissue is 
A

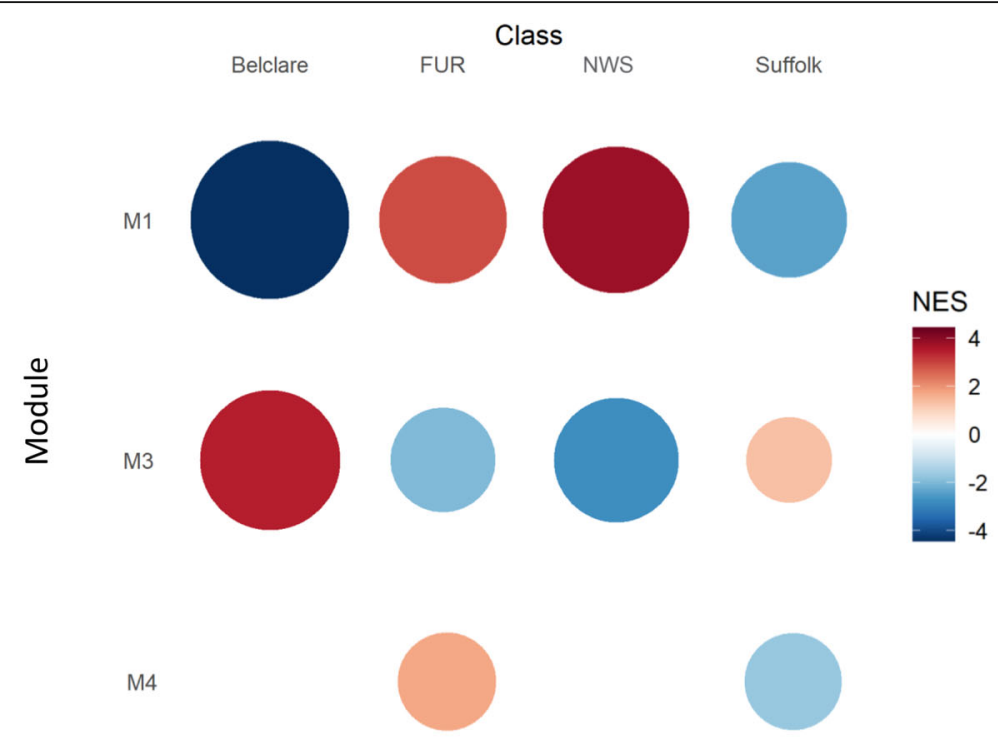

B

\section{M1}

GO_COLLAGEN_CONTAINING_EXTRACELLULAR_MATRIX-

GO_MUSCLE_CONTRACTION -

GO_CONTRACTILE_FIBER -

GO_MUSCLE_SYSTEM_PROCESS -

GO_EXTRACELLULLAR_MATRIX_STRUCTURAL_CONSTITUENT -

GO_I_BAND -

GO_ENDOPLASMIC_RETICULUM_LUMEN -

GO_STRUCTURAL_CONSTITUENT_OF_MUSCLE -

GO_EXTRACELLULAR_STRUCTURE_ORGANIZATION -

GO_MYOFIBRIL_ASSEMBLY -

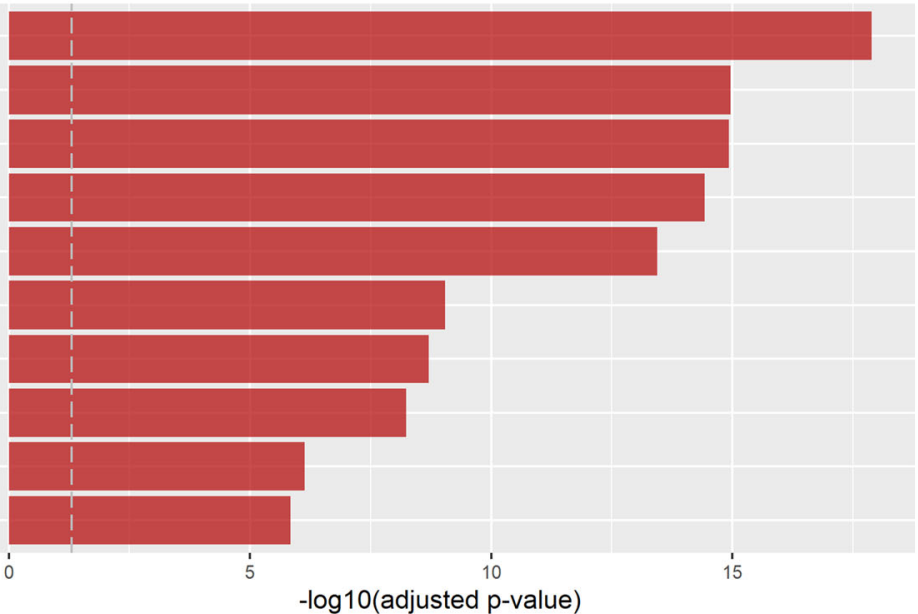

M4

GO_CORNIFICATION -

GO_KERATINOCYTE_DIFFERENTIATION -

GO_EPIDERMIS_DEVELOPMENT -

GO_SKIN_DEVELOPMENT -

GO_EPIDERMAL_CELL_DIFFERENTIATION

GO_KERATINIZATION -

GO_CORNIFIED_ENVELOPE -

GO DESMOSOME-

GO_REGULATION_OF_PEPTIDASE_ACTIVITY -

GO_PEPTIDE_CROSS_LINKING -

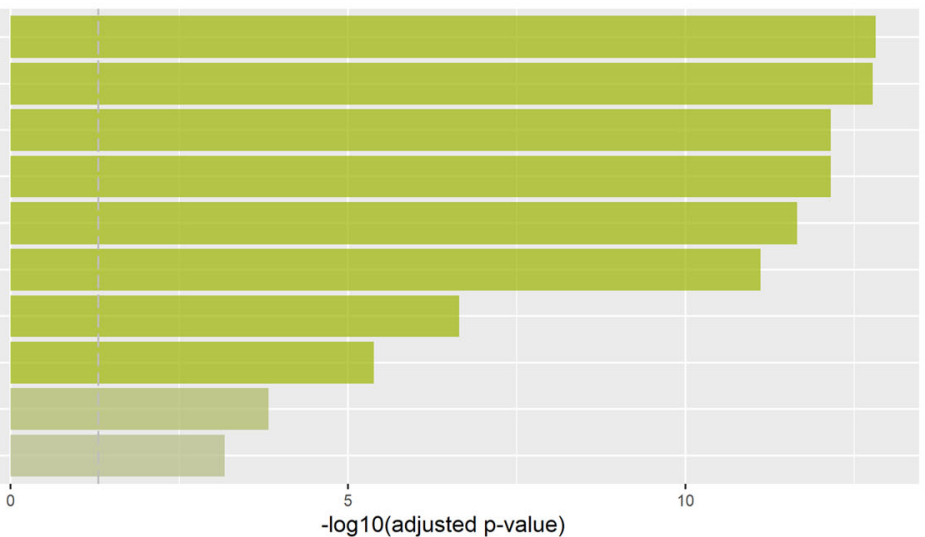

Fig. 3 Gene co-expression analysis across the four ewe breeds (Suffolk, Belclare, Fur and NWS) at the follicular phase of a natural oestrous cycle. A Gene set enrichment analysis identified module 1 and 4 to differ between Irish and Norwegian ewe breeds. B Over-representation analysis of genes showed the gene ontology terms in module 1 and 4 . The size of the circle is proportional to its normalized enriched score (NES) value. NWS $=$ Norwegian White Sheep 
predominantly composed of fibroblasts, smooth muscle and immune cells forming part of an ECM which is rich in collagen, hyaluronan and proteoglycans [11]. The cervical tissue also consists of epithelial cells which come in direct contact with pathogens. Therefore, an effective communication between the epithelial and immune cells in the cervical tissue is essential to maintain the integrity of the physical barrier against pathogens. Here, we hypothesised that differentially expressed genes and divergent biological processes would signpost biological phenomena that explain reasons for phenotypic differences in pregnancy rates between high and low fertility ewe breeds. We have identified for the first time extensive differences in the cervical transcriptome between high fertility Norwegian ewe breeds and the low fertility Suffolk breed. GO analysis of the DEGs in each comparison revealed novel enriched biological processes involved in muscle contraction, ECM development and immune response. In addition, co-expression analysis identified similar expression patterns related to muscle contraction and ECM development modules in both Norwegian ewe breeds, which were up-regulated compared to the low fertility Suffolk breed.

The stromal tissue (including smooth muscle and ECM) of the cervix undergoes to a cyclic remodelling across the phases of the oestrous cycle due to hormonal changes. High levels of oestradiol 2 at oestrus regulates oestrogen $\alpha$ (ESR1) and oxytocin receptors [12]. Oxytocin produces an increase of intracellular calcium levels in smooth muscle stimulating myometrial contractility [13]. Oxytocin also stimulates the production of PGE2 via prostaglandin endoperoxide synthase 2 (PTGS2 or COX-2), which affects both the ECM and smooth muscle of the cervical canal resulting in cervical softening and myometrial contractions [14]. Higher expression of muscle contraction and development pathways in the high fertility ewe breeds lead us to suggest that the cervix of these ewes is more susceptible to hormonal stimulation. Apart from the hormonal stimulation of the contractility, cervical smooth muscle is also responsive to inflammatory mediators [15] and even exert a reduced muscle contraction in the presence of Chlamydia infection as it was reported by Lee et al. (2020) [16]. Therefore, the cervical contractibility and its role in sperm transport merits further investigation.

COX-2 is involved in cervical softening and myometrial contractions [17]. However, COX-1 is involved in the maintenance of physiological events [18] in many tissues such as the gastrointestinal tract, kidneys, brain and in vascular smooth muscle of the reproductive tract $[19,20]$. Our results revealed that COX-1 was the gene with the highest difference in terms of FC between Fur and Suffolk, presenting higher levels of COX-1 in the low fertility Suffolk breed. In the digestive system, high levels of COX-1 and low levels of COX-2 contributes to gastric mucosal defence $[21,22]$. It has been described that prostaglandins produced by COX-1 regulate the mucosal blood flow and mucus secretion by the epithelial cells [22]. These studies and the higher levels of COX-1 found in the low fertility Suffolk breed could indicate an enhanced level of mucosal defence in Suffolk which is potentially maladaptive against frozen-thawed semen.

Differences in immune status of the sheep breeds are supported by the differential expression of multiple immune relevant genes in the Norwegian breeds (high fertility) compared to the low fertility Suffolk breed. The differential expression of multiple $\mathrm{CD}$ markers suggests divergent cell phenotypes or activation states are present. There were higher levels of expression of CD274 (also commonly referred to as PDL1) in both Norwegian ewe breeds compared to the low fertility Suffolk breed. CD274 acts to block T-cell activation and modulates the pro-inflammatory cytokine production, resulting in the suppression of cellular responses that clear the persistent human papillomavirus infection in cervical tissue [23]. The inflammatory chemokines CXCL9, CXCL10 and CXCL11 had higher levels in both Norwegian ewe breeds compared to Suffolk. These are predominantly involved in directing the migration of activated T-cells and natural killer cells and have been implicated in infection and inflammation [24]. It has been demonstrated that herpes simplex virus induces CXCL9 expression in human cervical epithelial cells [25] as well as CXCL10 in mice cervical cells [26], although its role in healthy cervical cells has not been studied yet. We identified the expression of genes encoding antimicrobial peptides such as the S100 proteins, a family of calcium-binding cytosolic proteins that have a broad range of intracellular and extracellular functions through regulating calcium balance, cell recruitment and inflammation [27, 28]. Members of the S100 family such as S100A8, S100A9, S100B and $S 100 A 12$ were up-regulated in the high fertility ewe breeds, suggesting higher protection against bacteria in the cervix of these ewe breeds. Proteomics studies using cervicovaginal mucus from women also detected the presence of members of the S100 family [29, 30]. In addition, Foley et al. (2015) [31] observed increased levels of S100A9 in endometrial biopsies of healthy cows compared to the group of cows with clinical endometriosis. Differential expression of specific TLRs, including TLR1 and TLR6 which detect lipopeptides, may hint at differences in the cervical microbiome between breeds [32]. Collectively, these results support a divergent immune response between ewe breeds, and implicate the regulation of inflammation as a key process differentiating the cervical transcriptomic response. Sub-optimal protection against bacteria in the cervix of the Suffolk may be one process which contributes to poorer reproductive outcomes. 
Results from the co-expression analysis revealed that pathways involved in cell-cell junction and desmosome had higher expression in Fur and lower expression in the low fertility Suffolk breed. The structure and configuration of the tight junctions has been reported to be modified by cytokines such as TNF $\alpha$ and TGF $\beta$ in epithelial cell lines [33], including uterine epithelium [34]. Although its role in the tight junctions between cervical epithelial cells has not been reported, we identified higher expression of TGF $\beta$ in high fertility ewe breeds compared to Suffolk, which could be indicative of good integrity of the cervical barrier in these ewe breeds thereby protecting sperm as they progress along the cervix.

\section{Conclusions}

In conclusion, the present study has defined, for the first time, the cervical transcriptome profile of four European ewe breeds with known differences in pregnancy rates following cervical AI with frozen-thawed semen. We identified extensive alterations in the cervical expression between high and low fertility ewe breeds, which were mainly involved in muscle contraction, ECM development and immune response. Further investigation in some specific genes related to the enriched pathways presented above as well as more functional studies of the products of these gene could assist in the improvement of sperm transport through the cervix following cervical AI with frozen-thawed semen and ultimate improve sheep fertility.

\section{Methods}

\section{Ethical approval}

Protocols were developed in accordance with the Cruelty to Animals Act (Ireland 1876, as amended by European Communities regulations 2002 and 2005) and the European Community Directive 86/609/EC. In Norway the study was approved by Norwegian Food safety Authority (FOTS ID 13168). In Ireland, all animal procedures were conducted under experimental license from the Health Products Regulatory Authority and the study was approved by the Teagasc animal ethics committee. This study was carried out in compliance with the ARRIVE Guidelines for reporting animal research [35].

\section{Experimental design and tissue collection}

The animal model has previously described by AbrilParreño et al. (2021) [9] since this experiment was performed as a part of larger study, which aimed to interrogate the ewe breed effect on mucus properties and anatomical characteristics across the oestrous cycle at both a synchronised and a natural oestrous. All the ewes used in this study were multiparous in a range of 4 to 5 years old. In this experiment, we examined the gene expression of the sheep cervix of four ewe breeds across two countries: Ireland (Belclare and Suffolk; high and low fertility, respectively) and Norway (NWS and Fur; both with high fertility compared to the Irish ewe breeds) at the follicular phase of a natural cycle. We used these ewe breeds due to their known different pregnancy rates following cervical/vaginal AI with frozenthawed semen. Suffolk ewes were the reference level (negative control) in this study as they have the lowest reported pregnancy rates [2]. Cervical tissue samples were collected post-mortem from the four ewe breeds at the follicular phase of a natural cycle $(n=8$ to 10 ewes per breed) approximately $12 \mathrm{~h}$ after fist observed in standing oestrus. All ewes were checked twice daily for signs of oestrus over a 6 day period using a teaser ram with an apron fitted (no semen/seminal plasma was allowed to be deposited into the vagina of the ewe). Following euthanasia, the ovaries were assessed for the presence of an active corpus luteum (luteal phase) or dominant follicles (follicular phase). The reproductive tracts were then longitudinally opened and two sections were taken from the mid region of the cervix. The midregion of the cervix was defined as the region between the first and the last cervical ring. The cervix is a rugged structure and therefore the folds were avoided.. All samples were snap-frozen in liquid nitrogen, and subsequently stored at $-80^{\circ} \mathrm{C}$ until RNA isolation.

\section{Tissue processing and RNA extraction}

Frozen cervical tissue immersed in TRIzol reagent was homogenized using a homogenizer (Bio-gen Pro200 Homogenizer, Pro Scientific) in order to lyse the tissue. The RNA extraction was completed using the RNeasy Kit (Quiagen Ltd., Crawley, West Sussex, UK) according to the manufacturer's instructions. Total RNA concentration was quantified using the Nanodrop ND-1000 UV-Vis Spectophotometer (NanoDrop Technologies Inc., Wilmington, DE, USA). Quality of RNA was ascertained with the use of 2100 Agilent Bioanalyzer (Agilent Technologies, Santa Clara, CA, USA). RNA integrity number (RIN) was greater than 7 in all samples and RNA aliquots were stored at $-80^{\circ} \mathrm{C}$ after extraction.

\section{Library preparation and RNA-sequencing}

RNA libraries were prepared for a total of 38 cervical tissue samples (Illumina ${ }^{\circ}$ TruSeq $^{\circ}$ Stranded mRNA Library preparation Kit) to convert mRNA into cDNA libraries for DNA sequencing. Briefly, this involved isolation of poly-A tailed mRNA using poly-T oligo attached magnetic beads, reverse transcription to form double stranded cDNA and the ligation of indexing adaptors. Indexes were allocated to specific samples prior to library construction so that each sample within a pool had a unique bar code. Following adapter ligation, DNA 
fragments were selectively enriched by performing PCR. Quality control checks were performed to assess the quality and quantity of the ds cDNA libraries. The Agilent 2100 Bioanalyzer (Agilent Technologies) was used to assess purity of the samples, using the Agilent DNA 1000 kit. Library quantity was measured using the Qubit fluorometer. These steps were previously reported by Brewer et al. 2020 [36]. All libraries were sequenced on an Illumina NovaSeq sequencer by Macrogen, Inc. (Seoul, Republic of Korea) where they were sequenced using an Illumina NovaSeq. Sequencing was performed for each sample at $2 \times 150$ bp paired end reads $(50 \mathrm{M}$ reads).

\section{Differential expression analysis}

Quality assessment of the raw sequence data was carried out using the software FastQC (v 0.11.8; http://www. bioinformatics.babraham.ac.uk/projects/fastqc/). Data were quality and adapter trimmed using the BBDuk java package to trim Illumina adapter sequences and any low quality bases (Phred score $<20$ ) from the $3^{\prime}$ end of sequence read pairs. Reads were aligned to the ovine genome Oar_v3.1 using the Spliced Transcripts Alignment to a Reference (STAR) aligner. A maximum of two mismatches with the reference genome were allowed and only uniquely mapped read pairs were retained for downstream analysis. Read counts overlapping all protein coding genes in the Oar_v3.1 Ensembl (v.95) annotation were estimated using featureCounts. To filter out lowly expressed genes, genes with less than one count per million in at least ten samples were discarded from the analysis. Remaining gene counts were normalized uses the median of ratios method as implemented in DeSeq2 (version 1.130.0) [37] to account for varying sequencing depth between samples. Transcript counts were modelled by fitting the data to a negative binomial distribution using genewise dispersion estimates and differentially expressed genes were identified with a generalized linear model likelihood ratio test. Statistical tests were corrected for multiple testing using the BenjaminiHochberg method. DEGs with an adjusted $P<0.05$ and a log2 FC threshold of 1.5 were used for further differentially expressed gene data exploration and pathway analysis.

\section{Functional and pathway enrichment analysis}

The gProfiler2 (v. 0.2.0) package was used to identify aggregated functional profiles of genes and gene clusters in the DEG lists. GO terms and Reactome pathways were analysed with an enrichment threshold cut-off of $P<0.05$. The R package rrvgo (v.1.1.4) was used to reduce the redundancy of significantly enriched GO terms by grouping similar terms based on their similarity within the GO hierarchy. Gene co-expression network analyses was carried out using the $\mathrm{R}$ package Cemitools (v1.14.0). For any modules identified a gene set enrichment analysis was carried out to indicate if each module was induced or repressed in the different ewe breeds. Finally, an over representation analysis was implemented to identify enriched biological functions in each module.

\section{Abbreviations \\ Al: Artificial Insemination; DEG: Differentially Expressed Gene; ECM: Extracellular Matrix; FC: Fold Change; GO: Gene Ontology; NWS: Norwegian White Sheep; PCA: Principal Component Analysis; PCR: Polymerase Chain Reaction; RIN: RNA Integrity Number; STAR: Spliced Transcripts Alignment to a Reference}

\section{Supplementary Information}

The online version contains supplementary material available at https://doi. org/10.1186/s12864-021-08060-9.

Additional file 1: Table S1. Top 5 differentially expressed genes (up and down-regulated) in Suffolk compared to Belclare. The genes shown in these tables were found to be significant with a $P<0.05$ and FC $>1.5$. Table S2. Top 5 differentially expressed genes (up and down-regulated) in Suffolk compared to Fur. The genes shown in these tables were found to be significant with a $P<0.05$ and FC $>1.5$.Table S3. Top 5 differentially expressed genes (up and down-regulated) in Suffolk compared to Norwegian White Sheep (NWS). The genes shown in these tables were found to be significant with a $P<0.05$ and $F C>1.5$.

Additional file 2: Table S4. Mapping information. Table S5. Differentially expressed genes (DEGs) in Suffolk compared to Belclare. Table S6. Differentially expressed genes (DEGs) in Suffolk compared to Fur. Table S7. Differentially expressed genes (DEGs) in Suffolk compared to Norwegian White Sheep (NWS).

Additional file 3: Table S8. List of biological processes up-regulated in Fur compared to Suffolk. Table S9. List of biological processes downregulated in Fur compared to Suffolk. Table S10. List of biological processes up-regulated in Norwegian White Sheep (NWS) compared to Suffolk. Table S11. List of biological processes down-regulated Norwegian White Sheep (NWS) compared to Suffolk.

\section{Acknowledgements}

The authors would like to acknowledge the help with the sampling of all the technical staff at Teagasc Research Centre, Athenry, Ireland. In Norway, the personnel working at the Section for Small ruminant research and herd health, NMBU - Faculty of Veterinary Medicine, Sandnes, Norway.

\section{Availability of data and material}

The datasets generated and/or analysed during the current study are available in the NCBI Gene Expression Omnibus https://www.ncbi.nlm.nih. gov/geo/ under accession number GSE179486.

\section{Authors' contributions}

SF, AK and XD conceived and designed the experiments, secured funding and overseen the work. LAP and AK collected the post- mortem samples from the ewes. LAP, KM interpreted the data and contributed to manuscript preparation. LAP performed the RNA extraction and drafted the manuscript. PC performed the statistical and bioinformatics analysis. All authors proof read the final manuscript.

\section{Funding}

The project was funded through the European Research Area Network, on Sustainable Animal Production (SusAN; Grant no. 16/RD/SusAn/ERA-NET). National funding was provided in Ireland by the Department of Agriculture, Food and the Marine as well as Teagasc (RMIS 0299) and in Norway by The Research Council of Norway (NFR 272338 / E50). 


\section{Declarations}

\section{Ethics approval and consent to participate}

This study was carried out in compliance with the ARRIVE Guidelines for reporting animal research [35]. Protocols were developed in accordance with the Cruelty to Animals Act (Ireland 1876, as amended by European Communities regulations 2002 and 2005) and the European Community Directive 86/609/EC. In Norway the study was approved by Norwegian Food safety Authority (FOTS ID 13168). In Ireland, all animal procedures were conducted under experimental license from the Health Products Regulatory Authority and the study was approved by the Teagasc animal ethics committee.

\section{Consent for publication}

Not applicable.

\section{Competing interests}

The authors declare that they have no competing interests.

\section{Author details}

'Laboratory of Animal Reproduction, Department of Biological Sciences, School of Natural Sciences, Biomaterials Research Cluster, Bernal Institute, Faculty of Science and Engineering, University of Limerick, Limerick, Ireland. ${ }^{2}$ Animal \& Bioscience Research Department, Animal \& Grassland Research and Innovation Centre, Teagasc, Grange, Co. Meath, Ireland. ${ }^{3}$ School of Agriculture and Food Science, University College Dublin, Belfield, Dublin 4, Ireland. ${ }^{4}$ Faculty of Veterinary Medicine, Norwegian University of Life Sciences, Ås, Norway. ${ }^{5}$ UMR 6175 INRA, CNRS-Université de Tours-Haras Nationaux, Station de Physiologie de la Reproduction et des Comportements Institut National de la Recherche Agronomique, Nouzilly, France.

Received: 26 July 2021 Accepted: 1 October 2021

Published online: 20 October 2021

\section{References}

1. Anel L, Kaabi M, Abroug B, Alvarez M, Anel E, Boixo JC, et al. Factors influencing the success of vaginal and laparoscopic artificial insemination in churra ewes: a field assay. Theriogenology. 2005;63(4):1235-47.

2. Donovan A, Hanrahan JP, Kummen E, Duffy P, Boland MP. Fertility in the ewe following cervical insemination with fresh or frozen-thawed semen at a natural or synchronised oestrus. Anim Reprod Sci. 2004;84(3-4):359-68.

3. Maxwell WMC. Artificial insemination of ewes with frozen-thawed semen at a synchronized oestrus. 1. Effect of time of onset of oestrus, ovulation and insemination on fertility. Anim Reprod Sci. 1986;10(4):301-8.

4. Paulenz H, Soderquist L, Adnoy T, Nordstoga A, Gulbrandsen B, Berg KA. Fertility results after different thawing procedures for ram semen frozen in minitubes and mini straws. Theriogenology. 2004;61(9):1719-27.

5. Fair S, Hanrahan JP, O'Meara CM, Duffy P, Rizos D, Wade M, et al. Differences between Belclare and Suffolk ewes in fertilization rate, embryo quality and accessory sperm number after cervical or laparoscopic artificial insemination. Theriogenology. 2005;63(7):1995-2005.

6. Fair S, Hanrahan JP, Ward F, O'Meara CM, Duffy P, Donovan A, et al. The difference in embryo quality between Belclare and Suffolk ewes is not due to differences in oocyte quality. Theriogenology. 2006;66(2):191-7.

7. Fair S, Hanrahan JP, Donovan A, Duffy P, O'Meara CM, Lonergan P, et al. Hormonal relationships during the periovulatory period among ewe breeds known to differ in fertility after cervical artificial insemination with frozen thawed semen. Anim Reprod Sci. 2007;97(3-4):284-94.

8. Richardson L, Hanrahan JP, O'Hara L, Donovan A, Fair S, O'Sullivan M, et al. Ewe breed differences in fertility after cervical Al with frozen-thawed semen and associated differences in sperm penetration and physicochemical properties of cervical mucus. Anim Reprod Sci. 2011;129(1-2):37-43.

9. Abril-Parreño L, Krogenæs AK, Byrne CJ, Donovan A, Stuen S, Caldas E, et al. Ewe breed differences in cervical anatomy and cervicovaginal mucus properties: An international study. Theriogenology. 2021;160:18-25.

10. Abril-Parreño L, Wilkinson H, Krogenæs A, Morgan J, Gallagher ME, Reid C, et al. Identification and characterisation of O-linked glycans in cervical mucus as biomarkers of sperm transport: A novel sheep model. Glycobiology. 2021. https://doi.org/10.1093/glycob/cwab085.
11. Anton L, DeVine A, Sierra L-J, Brown AG, Elovitz MA. miR-143 and miR-145 disrupt the cervical epithelial barrier through dysregulation of cell adhesion, apoptosis and proliferation. Sci Rep. 2017;7(1):3020.

12. Fleming JG, Spencer TE, Safe SH, Bazer FW. Estrogen regulates transcription of the ovine oxytocin receptor gene through GC-rich SP1 promoter elements. Endocrinology. 2006;147(2):899-911.

13. Arias F. Pharmacology of oxytocin and prostaglandins. Clin Obstet Gynecol. 2000;43(3):455-68.

14. Kershaw CM, Scaramuzzi RJ, McGowan MR, Wheeler-Jones CP, Khalid M. The expression of prostaglandin endoperoxide synthase 2 messenger RNA and the proportion of smooth muscle and collagen in the sheep cervix during the estrous cycle. Biol Reprod. 2007;76(1):124-9.

15. Shea-Donohue T, Notari L, Sun R, Zhao A. Mechanisms of smooth muscle responses to inflammation. Neurogastroenterol Motil. 2012;24(9): $802-11$.

16. Lee JM, Mayall JR, Chevalier A, McCarthy H, Van Helden D, Hansbro PM, et al. Chlamydia muridarum infection differentially alters smooth muscle function in mouse uterine horn and cervix. Am J Physiol Endocrinol Metab. 2020;318(6):E981-e994.

17. Kothencz A, Hajagos-Tóth J, Szűcs KF, Schaffer A, Gáspár R. a-Tocopherol Potentiates the Cervical Resistance Decreasing Effects of COX Inhibitors in Pregnant Rats: The Putative Role of Cyclooxygenase-2 Inhibition. J Pharmacol Exp Ther. 2019;368(2):292-8.

18. Clària J. Cyclooxygenase-2 biology. Curr Pharm Des. 2003;9(27):2177-90.

19. Marions L, Danielsson KG. Expression of cyclo-oxygenase in human endometrium during the implantation period. Mol Hum Reprod. 1999;5(10): 961-5.

20. Slater DM, Dennes WJB, Campa JS, Poston L, Bennett PR. Expression of cyclo-oxygenase types-1 and -2 in human myometrium throughout pregnancy. Mol Hum Reprod. 1999;5(9):880-4.

21. Kargman S, Charleson S, Cartwright M, Frank J, Riendeau D, Mancini J, et al. Characterization of Prostaglandin G/H Synthase 1 and 2 in rat, dog, monkey, and human gastrointestinal tracts. Gastroenterology. 1996;111(2):445-54.

22. Wallace $\mathrm{JL}$, Devchand PR. Emerging roles for cyclooxygenase-2 in gastrointestinal mucosal defense. Br J Pharmacol. 2005;145(3):275-82.

23. Yang W, Song Y, Lu YL, Sun JZ, Wang HW. Increased expression of programmed death (PD)-1 and its ligand PD-L1 correlates with impaired cell-mediated immunity in high-risk human papillomavirus-related cervical intraepithelial neoplasia. Immunology. 2013;139(4):513-22.

24. Metzemaekers M, Vanheule V, Janssens R, Struyf S, Proost P. Overview of the Mechanisms that May Contribute to the Non-Redundant Activities of Interferon-Inducible CXC Chemokine Receptor 3 Ligands. Front Immunol. 2017:8:1970.

25. Huang W, Hu K, Luo S, Zhang M, Li C, Jin W, et al. Herpes simplex virus type 2 infection of human epithelial cells induces CXCL9 expression and CD4+ T cell migration via activation of p38-CCAAT/enhancer-binding protein- $\beta$ pathway. J Immunol. 2012;188(12):6247-57.

26. Thapa M, Welner RS, Pelayo R, Carr DJ. CXCL9 and CXCL10 expression are critical for control of genital herpes simplex virus type 2 infection through mobilization of HSV-specific CTL and NK cells to the nervous system. J Immunol. 2008;180(2):1098-106.

27. Wang S, Song R, Wang Z, Jing Z, Wang S, Ma J. S100A8/A9 in Inflammation. Front Immunol. 2018:9:1298.

28. Xia C, Braunstein Z, Toomey AC, Zhong J, Rao X. S100 Proteins As an Important Regulator of Macrophage Inflammation. Front Immunol. 2018;8:1908.

29. Ferreira CST, da Silva MG, de Pontes LG, dos Santos LD, Marconi C. Protein Content of Cervicovaginal Fluid Is Altered During Bacterial Vaginosis. J Low Genit Tract Dis. 2018;22(2):147-51.

30. Lee D-C, Hassan SS, Romero R, Tarca AL, Bhatti G, Gervasi MT, et al. Protein profiling underscores immunological functions of uterine cervical mucus plug in human pregnancy. J Proteomics. 2011;74(6):817-28.

31. Foley C, Chapwanya A, Callanan JJ, Whiston R, Miranda-CasoLuengo R, Lu J, et al. Integrated analysis of the local and systemic changes preceding the development of post-partum cytological endometritis. BMC Genomics. 2015;16(1):811.

32. O'Neill LA, Golenbock D, Bowie AG. The history of Toll-like receptors redefining innate immunity. Nat Rev Immunol. 2013;13(6):453-60.

33. Capaldo CT, Nusrat A. Cytokine regulation of tight junctions. Biochimica et Biophysica Acta (BBA) - Biomembranes. 2009;1788(4):864-71.

34. Grant-Tschudy KS, Wira CR. Paracrine mediators of mouse uterine epithelial cell transepithelial resistance in culture. J Reprod Immunol. 2005;67(1-2):1-12. 
35. Kilkenny C, Browne WJ, Cuthill IC, Emerson M, Altman DG. Improving Bioscience Research Reporting: The ARRIVE Guidelines for Reporting Animal Research. PLOS Biol. 2010;8(6):e1000412.

36. Brewer A, Cormican P, Lim JJ, Chapwanya A, O'Farrelly C, Meade KG

Qualitative and quantitative differences in endometrial inflammatory gene expression precede the development of bovine uterine disease. Sci Rep. 2020;10(1):18275

37. Robinson MD, McCarthy DJ, Smyth GK. edgeR: a Bioconductor package for differential expression analysis of digital gene expression data. Bioinformatics (Oxford, England). 2010;26(1):139-40.

\section{Publisher's Note}

Springer Nature remains neutral with regard to jurisdictional claims in published maps and institutional affiliations.

Ready to submit your research? Choose BMC and benefit from:

- fast, convenient online submission

- thorough peer review by experienced researchers in your field

- rapid publication on acceptance

- support for research data, including large and complex data types

- gold Open Access which fosters wider collaboration and increased citations

- maximum visibility for your research: over $100 \mathrm{M}$ website views per year

At $\mathrm{BMC}$, research is always in progress.

Learn more biomedcentral.com/submissions 